\title{
Medical History Dictionary Derived Term
}

National Cancer Institute

\section{Source}

National Cancer Institute. Medical History Dictionary Derived Term. NCI Thesaurus.

Code C83346.

A medical history identifier obtained from a dictionary. 